Erratum

\title{
Sperm chromosome complements from two human reciprocal translocation heterozygotes
}

\author{
Elizabeth L. Spriggs ${ }^{1}$, Renee H.Martin ${ }^{1}$, Maj Hulten ${ }^{2}$ \\ ${ }^{1}$ Division of Medical Genetics, Department of Paediatrics, University of Calgary, and Medical Genetics Clinic, \\ Alberta Children's Hospital, 1820 Richmond Road, S.W., Calgary, Alberta T2T 5C7. Canada \\ ${ }^{2}$ Regional Cytogenetics Laboratory, East Birmingham Hospital, Birmingham, UK
}

Hum Genet (1992) 88:447-452

The captions for Figs. 1 and 2 were switched. The corrected text should read:

Fig. 1. Q-banded karyotype of a chromosomally balanced sperm bearing both translocated chromosomes from a $\mathrm{t}(11 ; 17)$ carrier, $23, \mathrm{X},-11,-17,+\operatorname{der}(11),+\operatorname{der}(17)$

Fig. 2. Q-banded karyotype of a chromosomally unbalanced sperm resulting from a crossover in the interstitial segment followed by $3: 1$ segregation from a $t(1 ; 11)$ carrier, $24, \mathrm{Y},-1,-11,+\operatorname{der}(1),+\operatorname{der}(1),+\operatorname{der}(11)$ 